\title{
Lectura fàcil per a nouvinguts: una possible eina per a l'ensenyament del català
}

\section{com a L2}

\section{Easy reading for newly arrived people: a tool to teach catalan as a $\mathrm{L} 2$}

\author{
Montserrat Morales Payà \\ Universitat de València \\ moipa@alumni.uv.es
}

Data de recepció: 26/06/2018

Data d'aceptació: 27/08/2018

\begin{abstract}
Resum
Llegir és una habilitat que permet compartir idees, pensaments i experiències. L'accés a la lectura és una necessitat social i un dret reconegut en diversos textos legals nacionals i internacionals, entre d'altres, les Directrius per a generar informació de lectura fàcil. Amb l'objectiu que una gran part de la població puga accedir-hi, l'Associació de Lectura Fàcil (ALF) ha impulsat durant més d'una dècada iniciatives perquè es publiquen documents i llibres de lectura fàcil (Mayol i Salvador, 2012).

Els materials de lectura fàcil (LF) s'adrecen a persones amb dificultats lectores que poden ser permanents (discapacitats psíquiques i físiques, senilitat...) o transitòries (immigració, incorporació tardana a la lectura, escolarització deficient...). El context intercultural actual urgeix de metodologies i materials que faciliten el procés d'ensenyament i d'aprenentatge del català com a segona llengua i, en aquest sentit, es poden fer servir materials de LF que s'adeqüen a les necessitats educatives de l'alumnat nouvingut.

En l'article presentem la revisió de publicacions que tracten sobre LF, sobretot els estudis publicats per entitats, com ara l'ALF o la Universitat de Barcelona, que treballen amb materials de LF i en fan difusió. En aquest context conceptual es planteja la possibilitat d'aprofitar els materials per a facilitar la lectura en català a aquest tipus d'alumnat.
\end{abstract}

Paraules clau: lectura fàcil; multilingüisme; ensenyament i aprenentatge de L2; diversitat; educació intercultural.

\begin{abstract}
To read is a skill that allows sharing ideas, thoughts and experiences. The access to the reading is a social need and a right recognised in several international legal texts, go in of other, the Easy-to-read European Guidelines. With the end that a big part of the population can access to information, the Associació Lectura Fàcil (ALF) has driven during more than a decade initiatives to publish easy-to-read materials (Mayol i Salvador, 2012).

The easy-to-read materials address to people with hampered readers that can be permanent (disabled psychic and physical) or transitory (immigration, late incorporation to the reading). The current intercultural context urges of methodologies and material that facilitate the process of education and of learning Catalan as a second language and, in this sense, we can use easy-to-read materials that is suitable for the educational needs of the newcomer pupils. The article presents the review of publications that treat on easy-to-read, especially the studies published by entities, such as the ALF or the University of Barcelona, that work with easy-to-read materials and do diffusion. In this conceptual context poses the possibility to take advantage of the materials to facilitate the reading in Catalan for the newcomers.
\end{abstract}

Keywords: easy-to-read; multilingualism; education and learning of L2; diversity; intercultural education. 
$-236-$ 


\section{Taula de continguts:}

1. Introducció

2. Què és la Lectura Fàcil?

3. Quin és el marc legal a la Unió Europea? I a les comunitats autònomes de l'Estat Espanyol?

3.1. El marc legal a Catalunya

4. Com es vertebra el circuit de Lectura Fàcil?

4.1. Serveis editorials

4.2. Formació

4.3. Accessibilitat informativa

4.4.Presència de la Lectura Fàcil en Internet i les xarxes socials

4.5. El foment de la lectura

5. De quins materials disposem? Aplicació a l'ensenyament del Català com a L2 per a nouvinguts

5.1. Recursos per a l'aula

6. Conclusions

Bibliografia 



\section{Introducció}

El projecte d'investigació que iniciem pretén difondre, implantar i desenvolupar la Lectura Fàcil al País Valencià. Aspirem a la creació de sinergies entre les entitats socials, les administracions i el sector privat per a conformar una xarxa en el foment i la creació de projectes de Lectura Fàcil. Ens centrarem, en aquest cas, en els materials que s'adrecen a un sector poblacional concret com és la gent nouvinguda en el context determinat de l'ensenyament.

En el diàleg interlingüístic, és a dir, en les relacions que s'estableixen entre les llengües, no podem actuar només com a parlants i els interlocutors exclusivament com a oients. A través del reconeixement mutu de les identitats i una ètica solidària serà que podrem construir una societat intercultural.

El diàleg intercultural suposa un enriquiment col·lectiu en qualsevol àmbit: llengua, cultura, art, gastronomia, política i, fins i tot, religió. Per a una societat intercultural el diàleg interlingüístic és cabdal, i, per aquest motiu, cal fer un esforç per a l'obertura a totes les llengües possibles, a totes les cosmovisions o concepcions antropològiques possibles.

Si tenim en compte dades estadístiques poblacionals actuals, ens adonem que a Catalunya, per exemple, hi ha un $14^{\prime} 5 \%$ de la població amb procedència estrangera (IDESCAT). O, al País Valencià, aquest percentatge és, aproximadament, d'un 17\% (IVE). Caldrà garantir la inclusió d'aquesta part de la població perquè hi haja una vertadera igualtat de drets. I, pel que fa a l'ensenyament del català com a L2, disposem dels materials de Lectura Fàcil adreçats específicament a persones nouvingudes, una eina ben útil en aquest sentit.

\section{Què és la Lectura Fàcil?}

Llegir és una habilitat que permet compartir idees, pensaments i experiències. L'accés a la lectura és una necessitat social i un dret reconegut en diversos textos legals nacionals $\mathrm{i}$ internacionals, entre d'altres, les Directrius europees per a generar informació de lectura fàcil 
(International League of Societies for Persons with Mental Handicaps European Association, 1998).

Els materials de Lectura Fàcil (LF) s'adrecen a persones amb dificultats en la comprensió lectora que poden ser permanents (patologies psíquiques i físiques, senilitat) o transitòries (persones nouvingudes, amb incorporació tardana a la lectura o amb una escolarització deficient).

El context intercultural actual urgeix de metodologies i materials que faciliten el procés d'ensenyament i d'aprenentatge del català com a segona llengua i, en aquesta línia, es poden fer servir materials de LF que s'adeqüen a les necessitats educatives de l'alumnat nouvingut.

En la societat de la informació actual cal atendre un sector important de la població (el $30 \%$ ) amb dificultats de lectura o de comprensió lectora. Aquest és un col·lectiu important que necessita un fons material específic per poder gaudir de la lectura, tenir accés a la cultura i dret a la informació.

Basat en el principi de la democràcia lectora i de la inclusió social, a través de la lectura, la LF és una via que permet enriquir la qualitat de vida d'aquestes persones. Una manera d'oferir materials de lectura, audiovisuals i multimèdia elaborats amb una cura especial perquè puguen llegir-los i comprendre'ls persones amb problemes de lectura i de comprensió lectora.

Les causes que provoquen problemes de lectura i de comprensió són ben diverses (migració, escolarització deficient, dislèxia, senilitat, discapacitat intel·lectual, etc.). La carència en la capacitat comunicativa en una societat de la informació i del coneixement pot derivar en la marginació d'aquest col·lectiu.

La LF vol aportar solucions i contribuir per a pal·liar aquest problema. Quines són les característiques de les persones a què s'adrecen els materials de Lectura Fàcil?

- Persones amb dificultats de lectura transitòries:

- Persones lectores amb suficiència limitada en la llengua oficial o predominant (Neolectors adults) 
- Persones nouvingudes i altres parlants de la llengua no nadiua

- Persones analfabetes funcionals i/o amb una deficiència educativa

- Persones en procés d'alfabetització

- Adolescents amb dificultats d'adaptació al currículum escolar o amb una escolarització deficient

- Persones amb dificultats de lectura permanents:

- Amb deficiències sensorials o físiques

- Amb trastorns neuropsicològics

- Persones grans, parcialment senils

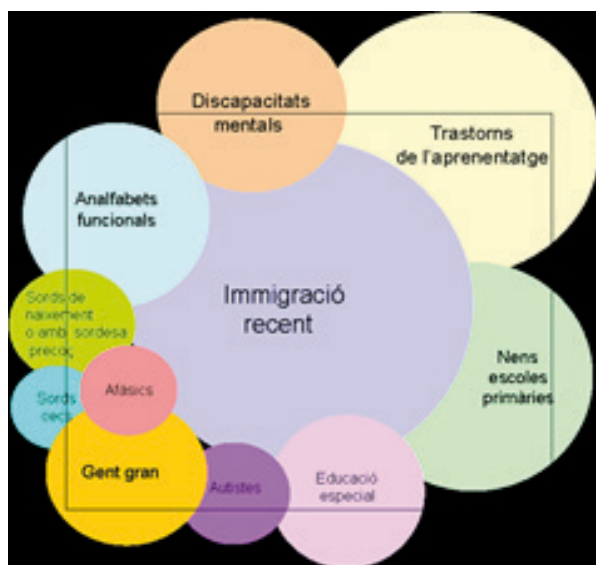

Figura 1.Relació entre els grups destinataris de LF (cercles) i la necessitat de material (quadrat). Font: ALF

\section{Quin és el marc legal a la Unió Europea? I a les comunitats autònomes de l'Estat}

\section{Espanyol?}

Segons s'afirma a les Directrius europees per a la informació de lectura fàcil: «la possibilitat de llegir aporta a les persones una enorme confiança, permet expandir les opinions i exercir un control sobre les pròpies vides. Les persones poden compartir idees, pensaments i experiències a través de la lectura, i créixer com éssers humans» (Ingemar, 1999). 
Però no tothom té la capacitat de llegir amb fluïdesa i el mode en què s'escriu o presenta la informació pot excloure moltes persones. Així, es crea una barrera entre allò que podem considerar informació rica i informació pobra, la qual cosa obstaculitza la igualtat de drets com a ciutadans/es i la participació plena en les respectives societats.

Les directrius pretenen servir d'ajuda per a superar aquest procés i donar suport als governs i organitzacions perquè facen els serveis d'informació i de documentació accessibles per a totes les persones, ja que la disponibilitat d'informació de LF a l'àmbit local, nacional i europeu beneficia tothom, no només les persones amb problemes per a llegir i escriure.

La intenció és que totes les persones de qualsevol país de la UE puguen utilitzar aquestes directrius per a generar un text accessible sobre qualsevol tema, de manera que és prioritari disposar d'informació simple, curta, relacionada amb la quotidianitat i que expresse el contingut de manera senzilla.

\subsection{El marc legal a Catalunya}

Amb l'objectiu de respondre a les necessitats socials d'una gran part de la població, la Generalitat de Catalunya ha promulgat la Llei 13/2014, del 30 d'octubre, d'accessibilitat. De la totalitat dels articles de la llei, en relació amb la LF, cal fer referència als següents:

Article 26. Condicions d'accessibilitat dels serveis d'ús públic

1. Els proveïdors de serveis d'ús públic han de proporcionar als usuaris que ho requereixin informació accessible sobre els serveis, que han de tenir disponible en documents en format de lectura fàcil, en sistema Braille, amb lletra ampliada o amb sistemes alternatius.

Article 29. Definicions

Als efectes del que disposa aquesta llei, s’entén per:

$[\ldots]$ 
i) Materials de lectura fàcil: els que han estat elaborats a partir de les directrius internacionals d'Inclusion Europe, xarxa europea de representació de les persones amb discapacitat intel·lectual, i de l'IFLA, federació internacional d'associacions de biblioteques, i que promouen una simplificació dels textos amb l'objectiu de fer-los accessibles a tota la ciutadania, simplificació que consisteix en la utilització d'un llenguatge planer i directe, un contingut assequible per als destinataris i un disseny que harmonitzi continguts i formes.

Article 32. Condicions d'accessibilitat en la comunicació de l'àmbit de l'ensenyament

1. Amb relació als alumnes amb discapacitat, el departament competent en matèria d'ensenyament:

c) Ha de garantir l'accés a materials educatius en format de lectura fàcil i amb lletra ampliada als alumnes que tenen dificultats de lectura degudes a discapacitats cognitives, trastorns de l'aprenentatge o altres factors causals, i ha de garantir que els professionals que han d'atendre aquests alumnes coneixen les estratègies d'aprenentatge i les ajudes tècniques adequades per a aquests casos.

Article 33. Accessibilitat en la comunicació en la relació amb les administracions públiques i amb els proveïdors de serveis públics

2. Les administracions públiques i els proveïdors de serveis públics han de facilitar a les persones amb discapacitats sensorials que ho requereixin l'accés a la informació, especialment la més rellevant, [...]. També han de promoure que textos d'interès públic i formularis d'ús freqüent s'ofereixin en format de lectura fàcil, en sistema Braille, amb lletra ampliada o amb altres sistemes [...].

Considerem que caldria promulgar un marc legal similar al País Valencià en què, a més a més, també es regule l'ús de materials de Lectura Fàcil en matèria educativa per tal que el dret a l'ensenyament amb unes condicions òptimes siga garantit a tot l'alumnat.

\section{Com es vertebra el circuit de Lectura Fàcil?}

L'Associació de Lectura Fàcil, constituïda a Catalunya l'any 2003, és un centre d'informació i de referència d'iniciatives a l'entorn de la LF. Impulsa l'accessibilitat informativa, s'imparteixen cursos i tallers i ofereix serveis editorials. 


\subsection{Serveis editorials}

- Edició i assessorament de textos de Lectura Fàcil

- Promoció d'un catàleg únic amb el segell comú LF

- Impuls d'una xarxa de llibreries de referència

Ofereixen els seus serveis a entitats, empreses i administracions interessades en fomentar l'accés a la lectura i a la informació de totes les persones, en especial d'aquelles que tenen dificultats lectores.

Des de 2002 han treballat amb:

- Administracions públiques

- Editorials

- Entitats

- Empreses

- Universitats

\subsection{Formació}

L'Associació Lectura Fàcil organitza cursos i tallers amb l'objectiu de fomentar la reflexió sobre la Lectura Fàcil i formar professionals interessats en produir textos clars i entenedors. Els professionals destinataris de la formació en LF pertanyen a àmbits o sectors diversos: l'administració, els serveis públics (com, per exemple, les biblioteques) i l'ensenyament.

Imparteixen cursos i tallers de:

- Redacció de textos en Lectura Fàcil 
- Redacció de textos en Llenguatge Planer

- Dinamització lectora

\subsection{Accessibilitat informativa}

Adapten a un llenguatge planer textos legals i documents informatius per a institucions i empreses que volen millorar la comunicació amb el seu públic destinatari. En aquest sentit, la concepció d'accessibilitat informativa es relaciona analògicament amb la d'accessibilitat arquitectònica.

\subsection{Presència de la Lectura Fàcil en Internet i les xarxes socials}

L'Associació de Lectura Fàcil (ALF) situa com a punt de referència la pàgina web que, amb més de 2.000 visites mensuals, esdevé punt de referència de la lectura fàcil (LF) i suport per a editorials, biblioteques, entitats, centres escolars i empreses interessades en el projecte Lectura Fàcil: http://www.lecturafacil.net/content-management/.

Entre 2010 i 2011, l'ALF ha obert nous canals de difusió com, per exemple, un mapa internacional de lectura fàcil, «una eina de consulta perquè els usuaris puguin trobar el club de LF o la llibreria de referència de LF més propers» (Mayol i Salvador, 2012). O, també, el butlletí electrònic mensual Infofàcil amb uns 2.500 subscriptors aproximadament. Així com també s'han obert perfils en les xarxes socials més populars com són Facebook; un compte de Twitter (@) Lectfacil); un canal a YouTube i el bloc de Lectura Fàcil.

\subsection{El foment de la lectura}

Un dels objectius principals de l'ALF és fomentar la lectura entre les persones que tenen dificultats o un hàbit de lectura insuficient. En aquest sentit, les novetats editorials i la dinamització a través dels clubs de LF tenen un paper fonamental dins l'Associació. 
Les novetats comercials de les editorials que participen del projecte són validades i difoses per l'ALF. A final de 2011, el catàleg de llibres de LF rondava els 125 títols en català i en castellà. Entre les editorials que cal destacar, hi trobem: Editorial La Mar de Fàcil (Col·lecció Aktual); Publicacions de l'Abadia de Montserrat (Col·leccions Llegim, l'Onada i Tant de Gust); Editorial Castellnou/Almadraba (Col·lecció Kalafat/Kalafate); Editorial Libros del Zorro Rojo (Col·lecció Cuentos del Mundo); Editorial Alqueria; Editorial Sirpus, i Llibre Obert.

A més a més, l'ALF també potencia i difon els clubs de LF, una de les eines més efectives per fer un bon ús dels llibres de LF i fomentar, així, la lectura entre els col·lectius menys propers a la literatura. A final de 2011, hi ha més de 100 clubs de LF a tot l'Estat Espanyol, 98 dels quals es duen a terme en biblioteques, escoles i entitats de Catalunya.

L'Associació també convoca el Premi Novel·la Curta de Lectura Fàcil, amb l'objectiu de trobar autors nous que escriguen en LF per ampliar el catàleg de llibres. El guanyador/a del premi rep la quantitat econòmica de 500 euros i es publica la seua obra.

Així com també, amb motiu de reconèixer l'esforç de biblioteques, entitats i centres escolars en el foment de la LF, l'ALF va iniciar l'any 2011 el Premi Bones Pràctiques LF, l'objectiu del qual és reconèixer les entitats que utilitzen de forma pràctica els materials de lectura fàcil.

Finalment, junt amb el préstec dels llibres a les biblioteques, la compra i la consulta de les primeres pàgines d'alguns llibres a través del web de l'ALF, les llibreries són la tercera via per als usuaris/es per contactar amb els llibres de LF.

L'Associació fomenta una xarxa de llibreries anomenades de referència, les quals tenen una selecció de llibres certificats com a LF, coneixen el projecte i poden assessorar els clients. Les llibreries de lectura fàcil es distingeixen amb un vinil que té el logotip de LF a la porta i, també, es pot usar el Mapa LF per cercar la llibreria de lectura fàcil més propera. 


\section{De quins materials disposem? Aplicació a l'ensenyament del Català com a L2 per a nouvinguts}

Tot seguit hi ha una sèrie de materials o recursos de LF, catalogats per l'Associació de Lectura Fàcil, per a l'ensenyament del català com a L2 i, també, per a l'ensenyament en català (com a llengua vehicular del procés d'ensenyament/aprenentatge).

La selecció present està elaborada a partir de la informació de la pàgina web adés esmentada, concretament, de la secció «Compartim materials» en què hi ha l'apartat «Recursos per a l'aula» ${ }^{1}$. De més a més, hi ha l'accés a uns altres materials de lectura fàcil com ara llibres editats en LF o el Butlletí Infofàcil.

Val a dir que l'aprofitament de tots aquests recursos millora exponencialment si en les aules treballem des d'una perspectiva pedagògica inclusiva i transformadora, tot aplicant algunes de les pràctiques més reeixides en l'educació, com ara la lectura compartida en tertúlies literàries dialògiques o el treball en grups interactius.

\subsection{Recursos per a l'aula}

D’una banda, per a les matèries de Ciències Naturals i de Ciències Socials, disposem de temaris per a l'alumnat de Primària i de Secundària amb dificultats de comprensió lectora adaptats a Lectura Fàcil sobre:

- Animals Invertebrats

- Animals Vertebrats

— Energia 1. Introducció a l'energia

— Energia 2. Fonts d'energia

1 Podeu consultar aquest material al següent enllaç: http://www.lecturafacil.net/content-management/29/173 
— Localitats

— Sistema digestiu

D'altra banda, es poden treballar la literatura i la lectura amb el suport dels materials següents:

a) Llibre Sarazad i les Mil i una nits: activitats per treballar i assolir les competències bàsiques del currículum escolar a partir del llibre de Lectura Fàcil Sarazad i les Mil una nits (Publicacions de l'Abadia de Montserrat).

b) Guia didàctica del llibre LF Mosaic de l'Editorial Castellnou (2008), editat amb el suport del Departament d'Educació de la Generalitat de Catalunya.

c) Activitats per l'alumnat i Guia didàctica del llibre LF Accents de l'Editorial Castellnou (2006), editat amb el suport del Departament d'Educació de la Generalitat de Catalunya.

d) Guies didàctiques dels llibres LF de la col·lecció Kalafat de l'Editorial Castellnou.Tots els llibres de la col·lecció Kalafat (català) i Kalafate (castellà) disposen d'una guia didàctica que es pot descarregar. Els llibres de la col·lecció són adaptacions dels grans clàssics de la literatura universal.

e) Llibre L'ocell de la felicitat: adaptació del conte tibetà feta per alguns alumnes de 1r d'ESO de la USEE (Unitat de Suport a l'Educació Especial) de l'IES de Terrassa. Curs 2011/2012.

f) Llibre L'home invisible: activitats prèvies a la lectura de L'home invisible (Castellnou), realitzats pels dinamitzadors del grup de LF de la Presó Model de Barcelona, Montse Flores i Xavier Vives.

g) Llibre Anna Frank. La seva vida: diferents recursos sobre el llibre Anna Frank. La seva vida (La Mar de Fàcil), creats per Montse Flores i Xavier Vives, dinamitzadors del Grup de Lectura Fàcil de la Presó Model de Barcelona.

Guia didàctica. Primera sessió (1 hora). 
Pel·lícules sobre l'holocaust jueu

Creació d'un diari

Creació d'un còmic

h) Projecte Llegim en Lectura Fàcil: Unitat de Suport a l'Educació Especial (USEE) de l'INS Maragall (Barcelona). Els alumnes de la USEE treballen durant el curs amb un llibre de Lectura Fàcil que els ajuda a assolir les competències bàsiques. Amb el llibre treballen diferents àrees curriculars.

i) Llibre L'illa del Tresor: activitats per desenvolupar les competències bàsiques a partir del llibre de Lectura Fàcil L'illa del tresor (Editorial Castellnou). Col·lecció Minikalafat. Adaptació de D. Fernández i M. Sintes, Barcelona, 2006.

Finalment, a la pàgina web de Jaume Serra trobem diversos recursos educatius com ara:

— Models d'enunciats de problemes matemàtics en Lectura Fàcil i exemples

— Models de comunicats en LF del centre educatiu a les famílies

— Guia per redactar textos en Lectura Fàcil

— Adaptació de la novel·la La fletxa negra de Robert L. Stevenson

\section{Conclusions}

Segons l'Associació de Lectura Fàcil, gairebé un 30\% de la població té dificultats de lectura i de comprensió lectora. La qual cosa implica, indefugiblement, que la capacitat comunicativa (comprensió i expressió oral/escrita) de moltes persones és insuficient i, en una societat de la informació i del coneixement — com ho és la nostra-, aquest fet pot desembocar en una desigualtat social greu. 
D’aquest percentatge de població, el sector o grup més exposat a aquesta desigualtat és el de les persones nouvingudes i, per tant, és el grup que més urgeix de material de Lectura Fàcil. Per tal de pal·liar aquest fet, es pot fer úsd'aquest tipus de material com un recurs per a l'ensenyament/aprenentatge del Català com a L2 i com a llengua vehicular.

A més a més, l'aplicació de noves metodologies i de pràctiques pedagògiques inclusives en l'educació fomenta la inclusió social i cultural de les persones en risc d'exclusió, si més no. Ara cal aplicar aquestes metodologies amb el suport de materials editats en LF a la pràctica de la docència quotidiana als centres d'ensenyament de la Conselleria d'Educació, Cultura, Investigació i Esport de la Generalitat Valenciana per tal de seguir-hi investigant. 


\section{Bibliografia}

Ingemar, B. (1999). Directrius per a materials de lectura fàcil. Barcelona: Col·legi Oficial de Bibliotecaris-Documentalistes de Catalunya. Disponible a: $<$ http://www.ifla.org/files/ assets/hq/publications/professional-report/prof-report-54-ca.pdf $>$ [Última consulta: 01/05/15].

ILMSH European Association. (1998). «El camino más fácil. Directrices europeas para generar información de fácil lectura destinada a personas con retraso mental». Disponible a: http://www.sidar.org/recur/desdi/pau/directriceseuropeas\%20para $\% 20$ facilitar\%20 la\%20lectura.pdf $>$ [Última consulta: 01/05/15].

Mayol, C. i Salvador, E. (2012). «La lectura fàcil: accions més destacables del bienni 20102011», Anuari de l'Observatori de Biblioteques, Llibres i Lectura 2010-2011, pp. 98-105. Barcelona: Universitat de Barcelona. 